\title{
CIDADE NASCENTE: PROPOSTA DE PROJETO PARA O CONCURSO BID URBANLAB BRASIL
}

CIUDAD NACIENTE: PROPUESTA DE PROYECTO PARA EL CONCURSO BID URBANLAB BRASIL

SPRING CITY: PROJECT PROPOSAL FOR THE CONTEST BID URBANLAB BRASIL

\section{FARIAS, HELIO TAKASHI MACIEL DE}

Arquiteto e Urbanista, Doutor em Arquitetura e Urbanismo, Professor Adjunto do Departamento de Arquitetura da Universidade Federal do Rio Grande do Norte. Email: htmfarias@gmail.com

\section{JONAS JUNIOR, LENILSON MIRANDA}

Arquiteto e Urbanista, Mestrando em projeto morfologia e tecnologia do ambiente construído, Universidade Federal do Rio Grande do Norte, Especialista em MBA em Design Thinking, UnyLeya. E-mail: Ienilsonjonas@gmail.com

\section{SOUZA, IRAN LUIZ SEABRA}

Arquiteto e Urbanista, Mestrando em projeto morfologia e tecnologia do ambiente construído, Universidade Federal do Rio Grande do Norte, pós-graduando no Master em Arquitetura, design de interiores e lluminação, Universidade Potiguar. E-mail: iran.arq@gmail.com

\section{INTRODUÇÃO: PROPOSTA DE PROJETO PARA O CONCURSO BID URBANLAB BRASIL}

Este artigo tem por objetivo de apresentar a proposta de intervenção urbana para bairro Ribeira, em Natal, $\mathrm{RN}$, desenvolvida para o concurso de projeto BID Urban Lab, 1ำ edição no Brasil. O concurso foi organizado pelo Banco Interamericano de Desenvolvimento (BID), Prefeitura do Natal, Caixa Econômica Federal e Ministério das Cidades, como meio de incentivar novos projetos urbanos para o bairro e promover uma rede participativa e inovadora que coloque em discussão os paradigmas do urbanismo sustentável na cidade. 0 texto do artigo traz brevemente a idealização do projeto de intervenção urbana proposto pela equipe denominada Cidade Nascente.

De acordo com as normas do concurso, as equipes participantes deveriam ser multidisciplinares e poderiam ser formadas por estudantes de graduação, pós-graduação e jovens profissionais (com até 3 anos de formados em universidades brasileiras). A equipe autora deste projeto foi constituída por dois jovens arquitetos - Lenilson Jonas e Marilia Carvalho; um pós-graduando em arquitetura, design, interiores e iluminação - Iran Luiz Souza; e quatro estudantes de arquitetura e urbanismo - Filipe Amorim, Ruan Henrique, Juliana Silva (UFRN) e Sofia Coura (UNP). A equipe foi orientada e supervisionada pelo professor Hélio Takashi Maciel de Farias, docente do Departamento de Arquitetura da UFRN.

Foi designado às equipes participantes do concurso o objetivo de desenvolver um projeto urbanístico, social e patrimonial integrado, multissetorial, inovador e sustentável para o bairro Ribeira, na cidade de Natal, capaz de gerar impactos positivos para a cidade e municípios vizinhos e oportunidades para os habitantes, convertendo-se em exemplo de regeneração urbana sustentável para outras cidades brasileiras.

Foi adotado um método de projeto baseado no processo de Design Thinking (Brown, 2010) de modo a se usar estratégias de estímulo à criatividade e ideias acessíveis à realidade local, que refletissem as necessidades dos usuários. As atividades foram organizadas dentro do processo de projeto, como proposto por Lawson (2011), em um ciclo com as etapas de análise, síntese e avaliação. A estrutura do texto está organizada na apresentação da área; idealização do conceito; explicação do masterplan; apresentação dos setores de projeto; e considerações finais. 
Farias, H. T. M.; Jonas Junior, L. M.; Souza, I. L. S.

\section{DESENVOLVIMENTO DA PROPOSTA}

\section{1 ÁREA}

A área de intervenção projetual está localizada no bairro Ribeira (Figura 1), zona leste de Natal, Rio Grande do Norte. Dispõe de reconhecido valor cultural, paisagístico e patrimonial, constituindo parte do centro histórico da cidade, estando situada às margens do Rio Potengi. O bairro abriga usos residenciais, comerciais e institucionais, com populações de moradores e usuários que abarcam classes sociais distintas, usuários de uma infraestrutura urbana consolidada, porém ociosa e degradada. A escassez de diferentes usos de valorização social da população do entorno, bem como a ausência de mecanismos efetivos de incentivos financeiros e da apropriação dos espaços urbanos pelas populações das áreas próximas são os principais problemas que atingem a totalidade da poligonal de tombamento da Ribeira e dos bairros adjacentes.

Figura 1: Foto aérea do bairro da Ribeira, destacado a poligonal da área de projeto.

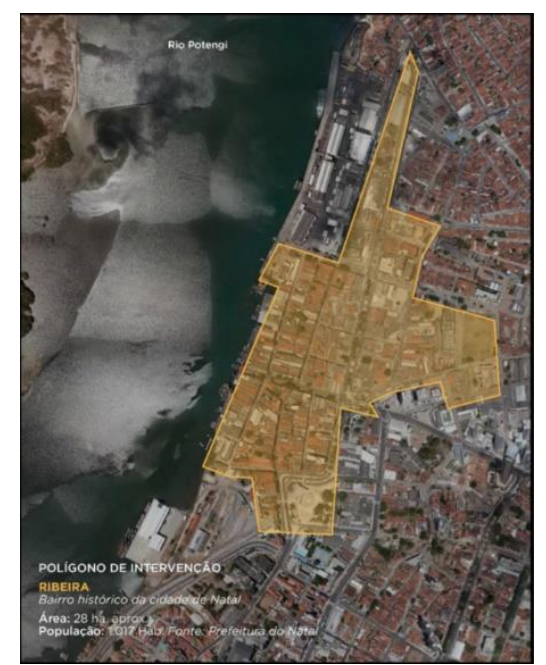

Fonte: Prefeitura Municipal de Natal (2017).

A Ribeira foi uma das primeiras unidades urbanas consolidadas de Natal, mas sofreu ao longo dos anos com processos de enfraquecimento de sua vitalidade. Na Figura 2, podemos observar: A - ruas do centro histórico e casarios em condições de degradação; $B$ - edificações de interesse patrimonial abandonados e em ruínas; C - comunidade de baixa renda sem infraestrutura básica; D - Espaços públicos e de lazer em péssimas condições para uso. Essa avaliação da situação foi fundamental no desenvolvimento da proposta.

Figura 2: Degradação do patrimônio arquitetônico e infraestrutura no bairro da Ribeira

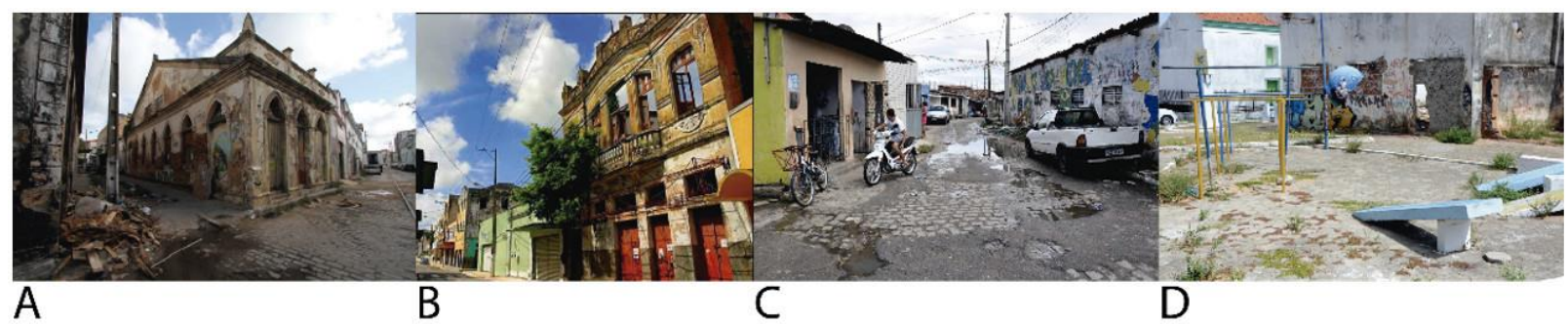

Fonte: BID UrbanLab Brasil (2017).

\subsection{CONCEITO DO PROJETO}

O Rio Potengi é o grande orientador da identidade do projeto que denominamos "Cidade Nascente", conceito de projeto que informou os caminhos de intervenção no sentido de desenvolver um plano que se propõe na escala do bairro Ribeira, mas que exerce influência também nos bairros vizinhos. Refletindo sobre a ideia do fluxo natural de um rio, a "nascente" deste conceito é o ponto de partida, simbolizando o projeto que apresentamos; por sua vez sucedida pelos "afluentes" na forma das vias primárias conectadas à Ribeira; 
pelos "meandros" representados pelas vias secundárias; e pelas "barragens" concretizadas no espaço privado. Por fim, a convergência desses planos de escala menor, indicam a "foz" nos demais bairros da cidade que seriam influenciados pelo projeto, aludidos, aqui, como as próximas áreas urbanas merecedoras de planos estratégicos semelhantes. A identidade pesqueira presente na tradição dos bairros da Ribeira, Rocas e Santos Reis é utilizada como referência para classificar as diferentes escalas das intervenções propostas. Assim, da maior dimensão para a menor, as intervenções são nomeadas de "Bote", "Baiteira" e "Catraia".

Figura 3: Conceito do projeto.

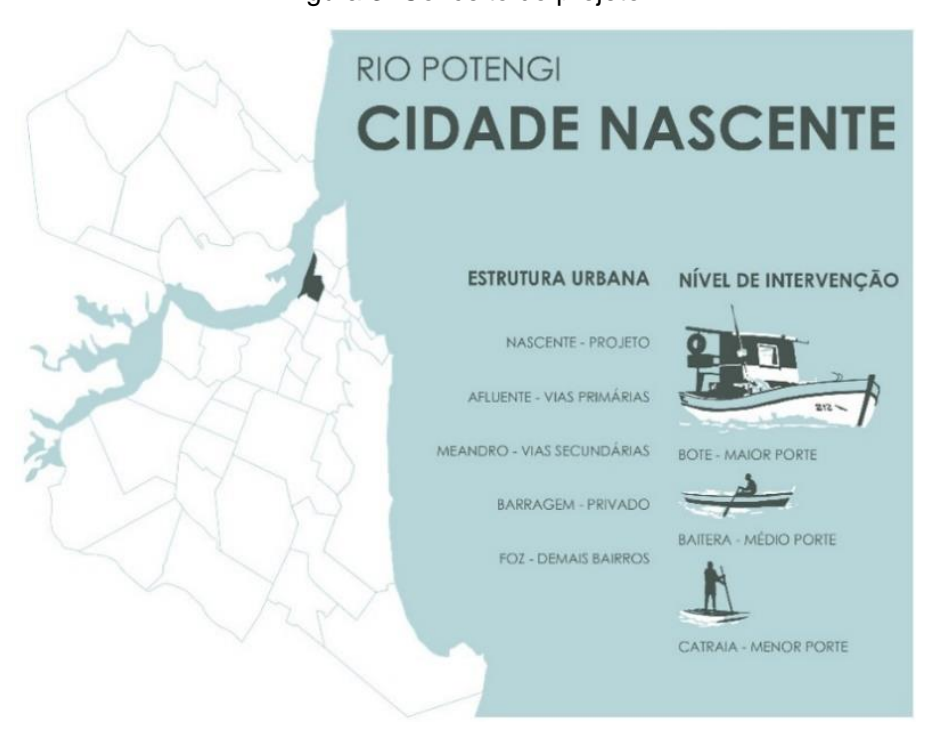

Fonte: Equipe Cidade Nascente, BID UrbanLab Brasil (2017).

\section{Campos-conceito}

Para reflexão do projeto, foram destacados 4 campos-conceito para as intervenções - a comunidade, a cultura, a paisagem e os mercados (Figura 4). Através da intervenção proposta, a comunidade se fortalecerá a partir da integração dos espaços públicos coletivos, centros comunitários, comércio e serviços reestruturados; na cultura, o projeto resgata a vocação cultural e histórica da Ribeira com a reativação de teatros, comércios especializados na culinária potiguar e espaços oportunos para apresentações culturais de médio e grande portes; no âmbito da paisagem, é oferecida à população uma nova experiência de desfrute, a partir da melhoria da infraestrutura urbana, reformas dos conjuntos edificados e do novo espaço de interação com o Rio Potengi; a valorização dos mercados enquanto pólos tradicionais de comércio e lazer para o cidadão favorece o usufruto do potencial turístico da região. As intervenções destes campos estão focadas na oferta de nova infraestrutura e equipamentos que visam fortalecer o patrimônio a partir da perspectiva do desenvolvimento e da inclusão social.

Figura 4: campos-conceitos e ligação com as intervenções na infraestrutura, patrimônio, desenvolvimento e inclusão social.

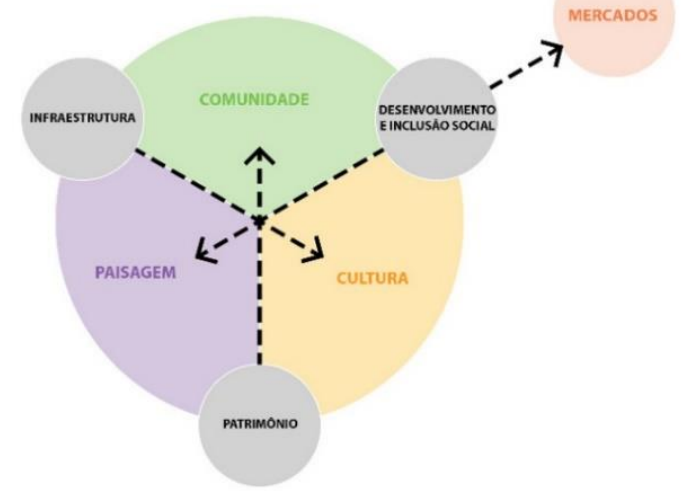

Fonte: Equipe Cidade Nascente, BID UrbanLab Brasil (2017). 
Farias, H. T. M.; Jonas Junior, L. M.; Souza, I. L. S.

\subsection{MASTERPLAN}

O projeto busca fortalecer o bem-estar social da população residente e visitante, requalificando o ambiente urbano e ativando os usos potenciais dos edifícios subutilizados. Este fim será alcançado através da valorização da identidade da população residente no bairro, da melhoria da infraestrutura local e da promoção de ações educacionais, culturais, comerciais e de lazer. A comunidade fortalecida fará com que o bairro se torne atrativo também para os visitantes - sejam estes usuários transitórios, empreendedores ou turistas. Na Figura 5 observam-se os 3 setores em destaque que serão utilizados para ilustrar as ideias de projeto.

Figura 5: Masterplan e principais intervenções no projeto.

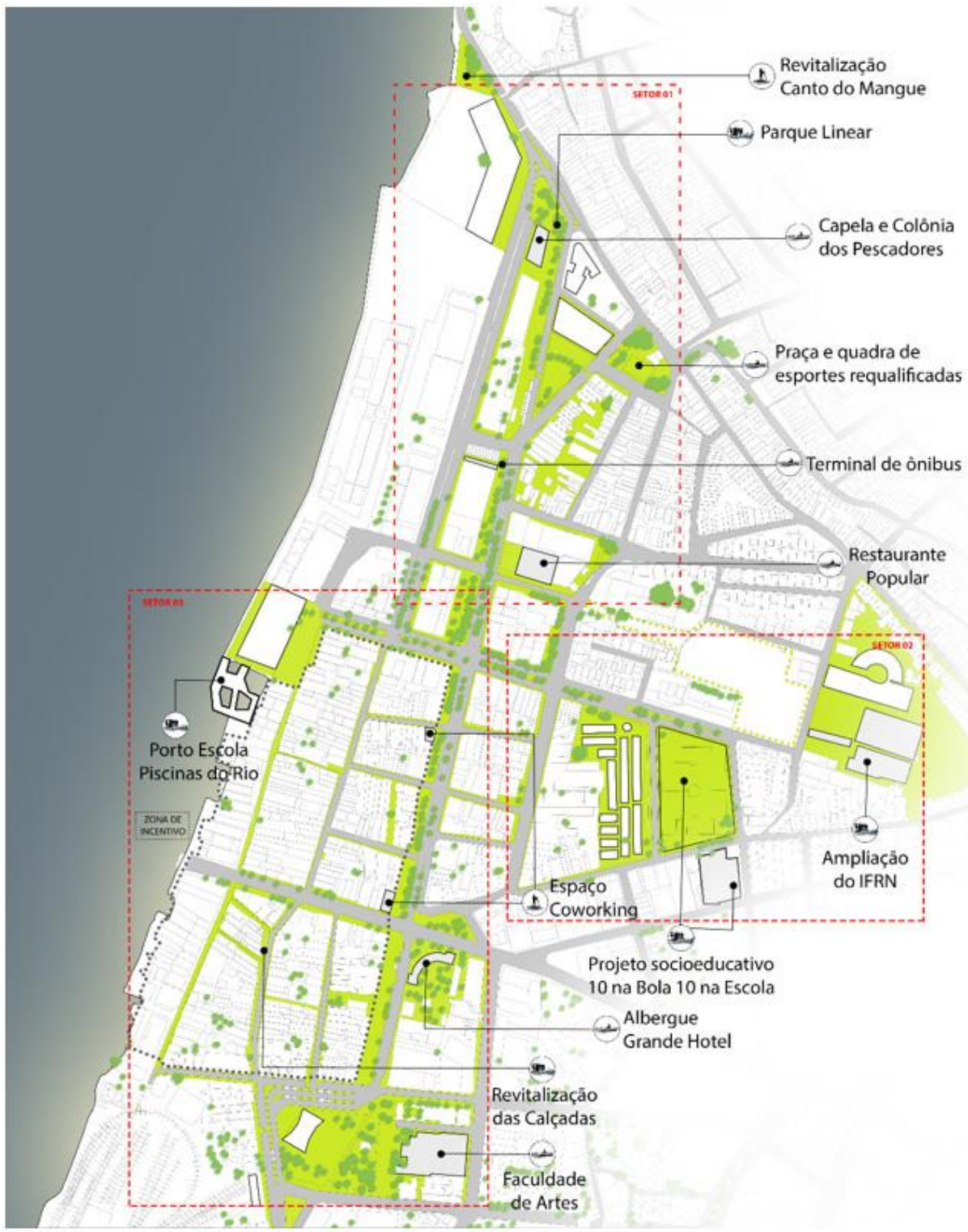

Fonte: Equipe Cidade Nascente, BID UrbanLab Brasil (2017).

\section{Setor 01}

O primeiro setor (Figura 6) a ser destacado traz as principais propostas para a área da antiga comunidade do Maruim (recentemente realocada para o bairro vizinho das Rocas), praça do mercado das Rocas e parte da Avenida Duque de Caxias, que conecta diretamente os bairros Ribeira e Rocas. Este setor prioriza a requalificação da moradia, qualidade de vida e trabalho da comunidade residente no bairro. Aproveitando uma proposta existente da Prefeitura de Natal, insere-se no setor o Centro Comercial Maruim para que os vendedores de peixe, camarão e outros frutos do mar possam continuar trabalhando na região na qual já desenvolvem suas práticas profissionais. Alguns galpões abandonados e pertencentes ao porto são 
transformados na capela e colônia dos pescadores, necessidade da comunidade apontada desde a ocupação do antigo Maruim. Indica-se a recuperação do hospital dos pescadores, que possui importante função de equipamento de interesse popular e está localizado na quadra da feira das Rocas. Esta quadra (figura) se conecta diretamente a uma intervenção linear em parte da Avenida Duque de Caxias, consistente da requalificação dos espaços públicos, neutralização de muros cegos e criação de equipamentos de descanso e lazer como lanchonetes, pistas de skate, quadra poliesportiva e mobiliário urbano com área sombreadas.

Figura 6: Propostas para o setor 01.

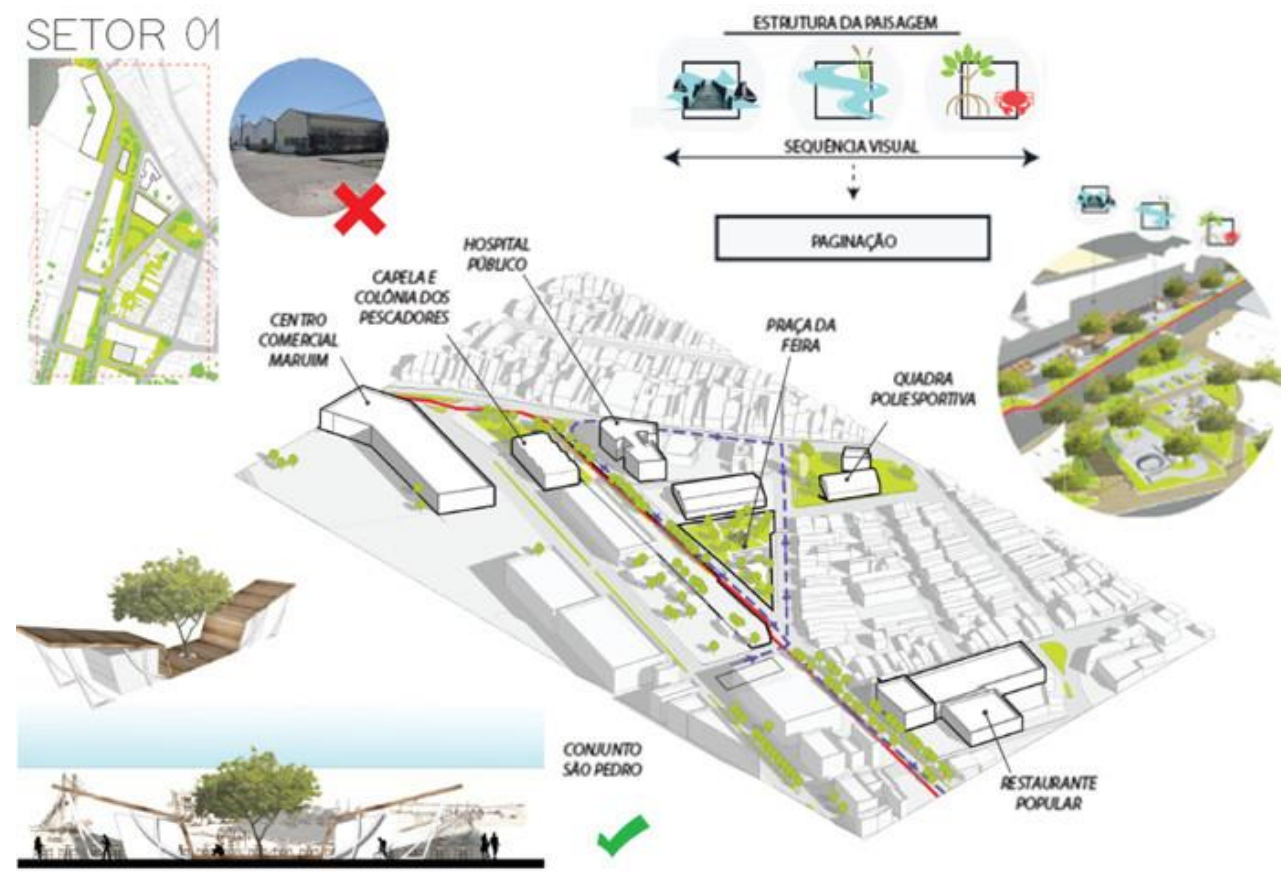

Fonte: Equipe Cidade Nascente, BID UrbanLab Brasil (2017).

Figura 7: Perspectiva da Quadra e da Feira conectada ao Parque Linear na Avenida Duque de Caxias.

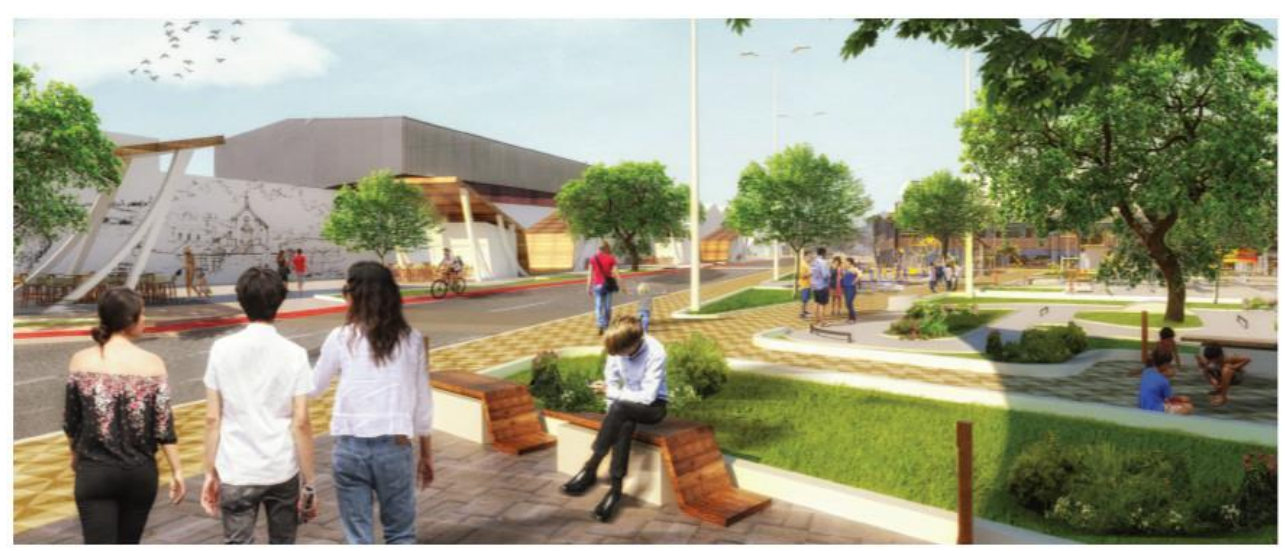

Fonte: Equipe Cidade Nascente, BID UrbanLab Brasil (2017).

\section{Setor 02}

O setor 02 corresponde à área do Conjunto São Pedro (para onde foi relocada a comunidade do Maruim), o estádio João Câmara, e o Instituto Federal do Rio Grande do Norte - Unidade Rocas. Este setor abriga a estrutura de equipamentos de lazer e educação (básica e profissionalizante) voltados para a população local. Para esta área propõe-se a conexão espacial contínua entre o estádio e o Conjunto São Pedro, reduzindo muros e abrindo os projetos socioeducativos aos olhos da comunidade e do entorno (projeto social 10 na bola 10 na escola). Ao lado do estádio, onde está situado o prédio da antiga sede da Secretaria Municipal de MeioAmbiente e Urbanismo, é proposto a reutilização de edificação existente para prática de novos esportes 
incluídos no projeto social como basquete, vôlei, danças e artes marciais. É prevista, para a sede do IFRN, a possibilidade de expansão do Instituto para receber novos cursos, inclusive de caráter profissionalizante destinados a jovens e adultos. Propomos, ainda, que os terrenos vazios da antiga estação ferroviária sejam preparados para expansão de projetos sociais e de criação de uma escola infantil.

\section{Figura 8: Propostas para o setor 02.}

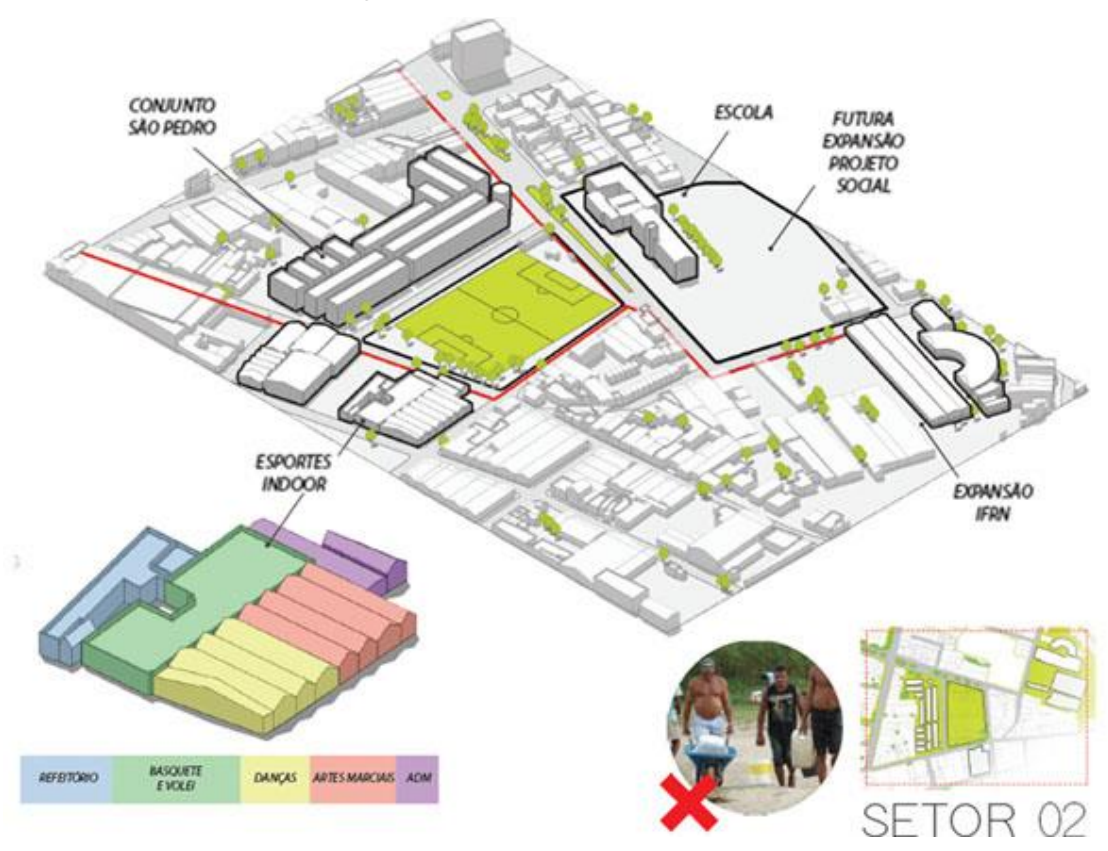

Fonte: Equipe Cidade Nascente, BID UrbanLab Brasil (2017).

\section{Setor 03}

O terceiro setor destacado (Figura 9) abrange o núcleo histórico do bairro e sua interface com o Rio Potengi. Para este setor, já mais adensado, propomos, por um lado, a reestruturação das vias exclusivamente para pedestres e daquelas com acesso de pedestres e automóveis; e por outro, a assimilação de novos usos nos edifícios subutilizados. A estratégia de incentivos aos usos adotada está baseada na Lei de Operação Urbana (2007), prevista como instrumento no Plano Diretor de Natal (2007).

Figura 9: Proposta para o setor 03 e lista de incentivos

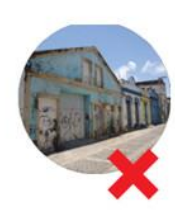

Incentivos aos usos:

A aplicaçăo de instrumentos previstos no Plano Diretor de Natal (2007) e na Lei de Operaçăo Urbana (2007) possibilitam o mo incentivo imobiliário e de infraestrutura, incentivando a ocupaçăo variabilidade de usos e requalificaçóes urbanas, oferecendo
crédito $e$ financiamento, bem como a utilizaçáo de programas governamentais existentes:

A-Reduçào/renegociaçào de IPTU e ISS (empreendedores, empresários e comerciantes:;

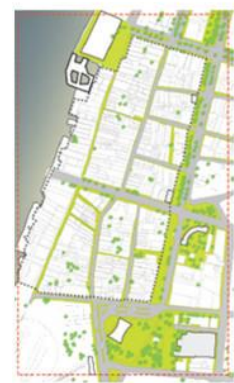

B-Implementaçào da Operaçào Urbana Consorciada intervençōes urbanas).

Incentivos de financiamento ecrédito aos uso:

C-Residéncia Universitária: Instituiçäo de Ensino (UFRN IFRN) direciona o auxilio moradia concedido aos estudantes D. Crédito as Cooperativas Locais: os bancos receber a garantia das cooperativas, que direcionam os valores aos cooperados cadastrados, em forma de aluguel e compra;

E-Minha Casa, Minha Vida: programa governamental de financiamento Eabitacional paracidadios de baixarenda

F- Cartão Reforma: programa governamental que oferece financiamento

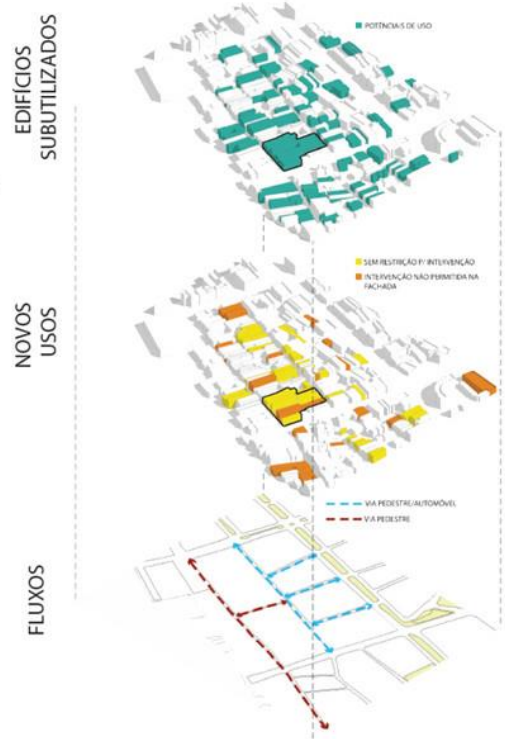

Fonte: Equipe Cidade Nascente, BID UrbanLab Brasil (2017).

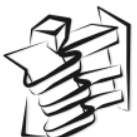


Farias, H. T. M.; Jonas Junior, L. M.; Souza, I. L. S.

Estes incentivos visam a ocupação com usos variados e requalificação urbana, através da oferta de crédito e financiamento aos proprietários dos imóveis, utilizando-se de recursos previstos em programas governamentais existentes. Além dos novos usos, é prevista a revitalização de fachadas das edificações de valor patrimonial, de modo a valorizar a história do local e incentivar a diversificação dos usos, tanto diário quanto noturno (Figura 10).

Figura 10: Revitalização das Fachadas históricas
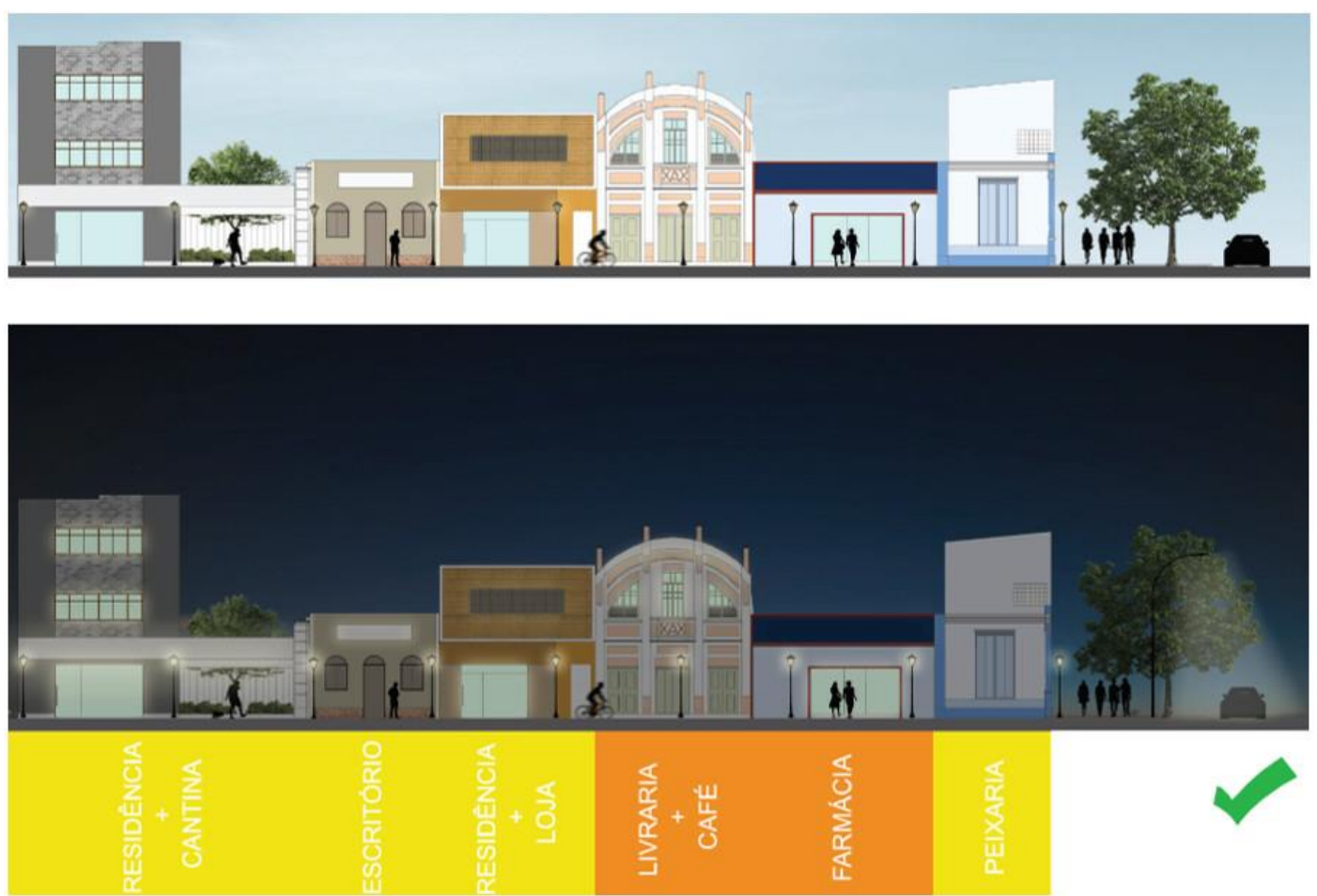

Fonte: Equipe Cidade Nascente, BID UrbanLab Brasil (2017).

No que diz respeito à interface com o rio, imaginou-se a reorganização do setor pesqueiro em direção ao posto da guarda costeira. Este deslocamento permite a revitalização das escolas de remo e a criação de um deck em madeira aberto à visitação pública, que oferece vista para o pôr do sol sobre o Potengi, mas também um posto de escola ambiental direcionado ao processo de despoluição do rio, dotada de piscinas naturais que demonstram o potencial de usufruto deste ambiente. Esse posto ambiental é destinado ao uso não apenas à comunidade local, mas também por visitantes oriundos de outras partes da cidade ou em passagem pelo terminal de passageiros do porto (figura 11).

Figura 11: Perspectiva do deck no Rio Potengi

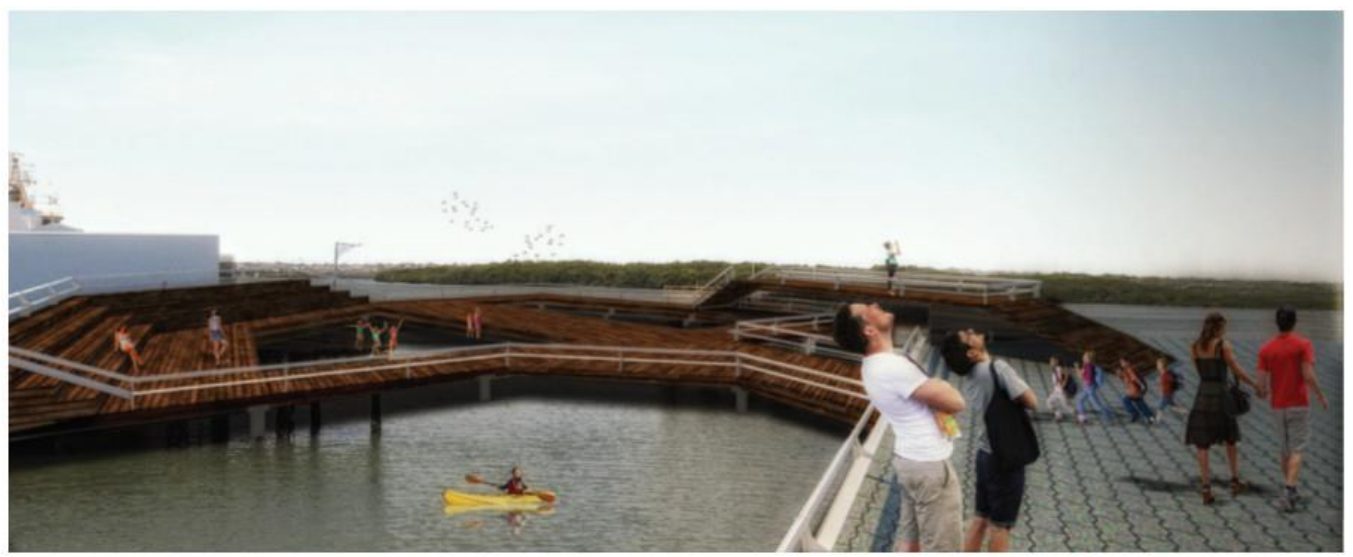

Fonte: Equipe Cidade Nascente, BID UrbanLab Brasil (2017). 
Farias, H. T. M.; Jonas Junior, L. M.; Souza, I. L. S.

\section{CONSIDERAÇÕES FINAIS}

A operacionalização deste projeto depende da revisão do instrumento da Operação Urbana Consorciada, de maneira a conectar o interesse público e privado através da proposta do Cidade Nascente. Ainda que os instrumentos da operação tenham sido abordados anteriormente em projetos que visavam a revitalização da Ribeira, os reflexos duradouros foram restritos. O diferencial da estratégia que adotamos está na priorização do incentivo à qualidade de vida e de trabalho da comunidade local e aos projetos sociais e econômicos originados da auto-organização destes moradores. O desenvolvimento deste potencial local figura, neste contexto, como principal ponto de atração para o investimento privado. Nossa proposta sugere a adaptação de projetos sociais existentes na área às perspectivas contemporâneas de empreendedorismo social, buscando retorno cultural e educativo, aliado ao desenvolvimento de grandes e pequenos negócios.

Imaginou-se que este processo possa ocorrer por etapas que partem da recuperação da infraestrutura atual, passando pelo desenvolvimento de novas oportunidades de emprego e atividades educativas para a comunidade, seguido por mudanças na infraestrutura de mobilidade e reativação de edificações abandonadas, gerando assim um aumento no fluxo de pessoas na área (figura 12). A proposta de transformação da realidade social e cultura urbana deverá incentivar o investimento proveniente de fontes privadas, que pode tornar sustentável a ampliação e manutenção das iniciativas importantes para o bairro.

Figura 12: Esquema de início aos incentivos na comunidade.

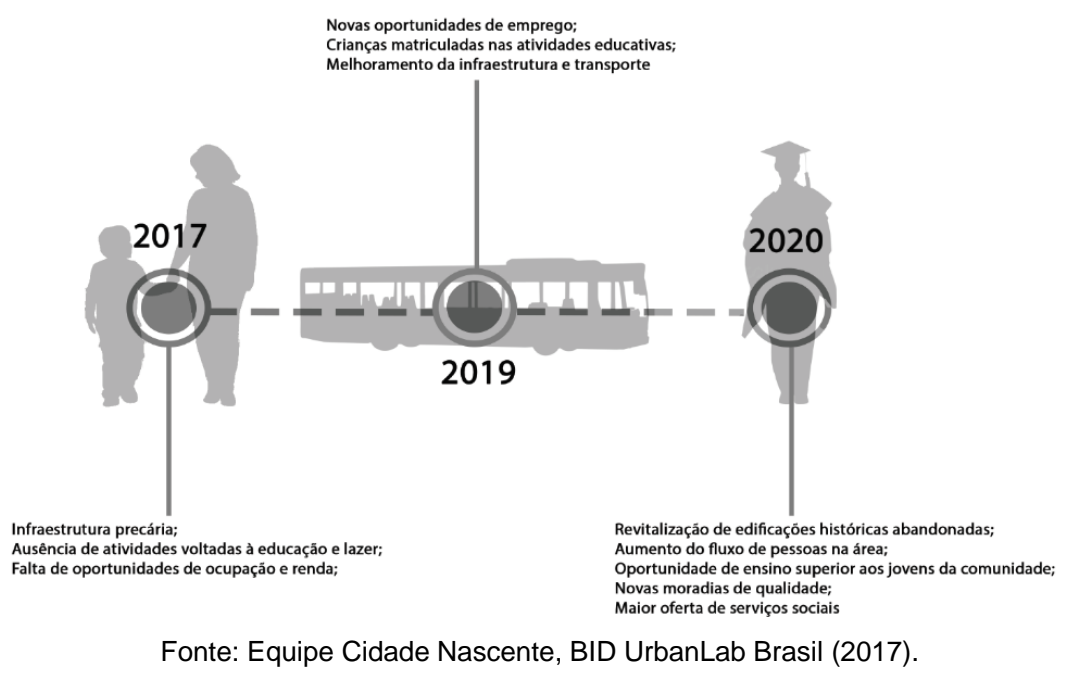

Todos os setores abordados fazem parte de um plano geral proposto por esta equipe, havendo ligações diretas entre o conceito, o projeto, a comunidade residente e as visões dos seus integrantes sobre a área. As propostas se interligam aliando soluções urbanísticas para problemas já existentes com novas alternativas baseadas na participação popular e na gestão integrada da área, assim como no respeito à cultura local e no desenvolvimento social e economicamente sustentável, questionando os modelos de intervenção até então aplicados na Ribeira. Desta forma, a "nascente" da nossa proposta encontra-se na valorização do bairro enquanto espaço de vida, trabalho, educação e consciência social - qualidades-chave para a requalificação sustentável dos valores patrimoniais, históricos, econômicos e turísticos da Ribeira.

\section{REFERÊNCIAS}

BROWN, T. Design Thinking: uma metodologia poderosa para decretar o fim das velhas ideias (Elsevier, Eds.). p. 249. Rio de Janeiro: Elsevier, 2010.

LAWSON, B. Como arquitetos e designers pensam. São Paulo: Oficina de Textos, 2011.

NATAL. Câmara Municipal. Lei Complementar nº 082, de 21 de junho de 2007. Dispõe sobre o Plano Diretor de Natal e dá outras providências. Natal, 2007.

Regras do concurso BID UrbanLab Natal Brasil, 1 a Edição Nacional. 2017. Organizado por: Banco Interamericano de Desenvolvimento (BID), a Prefeitura do Natal, a Caixa Econômica Federal, Ministério das Cidades.

NOTA DO EDITOR (*) O conteúdo do artigo e as imagens nele publicadas são de responsabilidade do(s) autor(es). 